
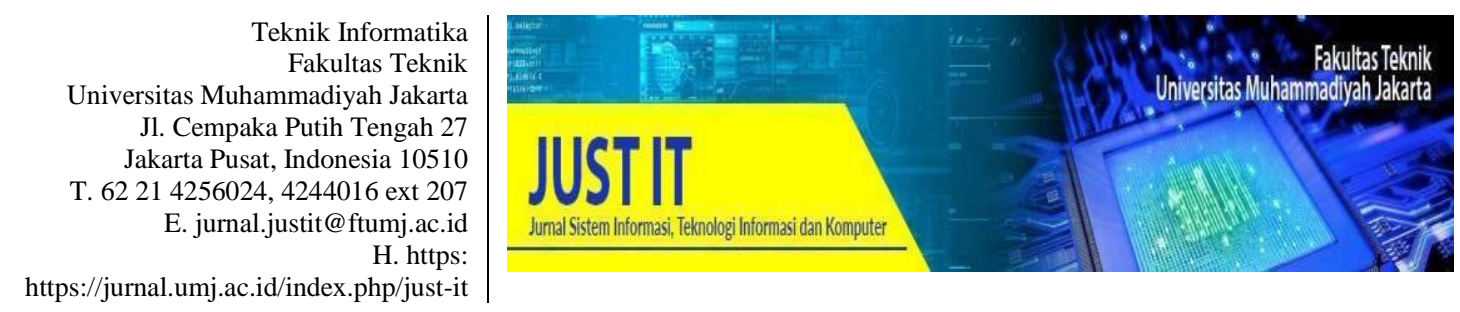

\title{
PEMODELAN DAN SIMULASI DISTRIBUSI KAOS CUSTOM DENGAN ANYLOGIC (STUDI KASUS KONVEKSI KAOS SURABAYA)
}

\author{
M Saifudin Azizi ${ }^{1}$, Yoga Aditiatama ${ }^{2}$, Moh Khusnul Mubarak ${ }^{3}$, Dwi Rolliawati ${ }^{4}$ \\ ${ }^{1,2,3,4}$ Fakultas Sains dan Teknologi Universitas Sunan Ampel Surabaya \\ msazizii1398@gmail.com,yogaaditiatama@gmail.com², khusnulmubar4@gmail.com³, \\ dwi_roll@uinsby.ac.id ${ }^{4}$
}

\begin{abstract}
Abstrak
Aktifitas bisnis yang bergerak pada bidang konveksi sangat bergantung pada proses produksi yang dilakukan. Efektivitas dan efesiensi perlu diperhatikan dalam menggunakan sumber daya manusia dan juga faktor manajemen. Konveksi kaos Surabaya memiliki banyak pelanggan di berbagai daerah di Surabaya, namun masih belum bisa memaksimalkan strategi kegiatan distribusi. Dengan menggunakan simulasi distribusi diharapkan bisa meningkatkan kualitas dari manajemen konveksi kaos surabaya dalam mengatur naik turunnya permintaan pelanggan, kualitas mutu pelayanan konveksi kaos surabaya meningkat, terutama dalam pengiriman oleh pihak distributor. Dengan menambahkan unit sesuai dengan jumlah retail maka ketepatan distribusi bisa mencapai $100 \%$.
\end{abstract}

Kata Kunci: distribusi, simulasi dan pemodelan, anylogic

\begin{abstract}
Business activities that function in the discipline of convection are very dependent on the production technique carried out. Effectiveness and effectivity want to be viewed in using human resources and also management factors. Surabaya T-shirt convection has many customers in more than a few regions in Surabaya, but still can't maximize its distribution strategy. By the use of distribution simulations it is hoped that it can improve the first-rate of Surabaya T-shirt convection administration in managing the ups and downs of patron demand, the exceptional of the service of Surabaya T-shirt convection increases. Especially in shipping by the distributor. By including units according to the variety of retails, the accuracy of distribution can reach $100 \%$.
\end{abstract}

Keywords: distribution, simulation and modelling, anylogic

\section{PENDAHULUAN}

Setiap kegiatan bisnis khususnya yang bergerak dalam bidang industri konveksi, kegiatan merubah bahan input menjadi barang output, yang kemudian dipakai atau dikonsumsi oleh konsumen sangat bergantung pada proses produksi yang dilakukan (Kusumawati, 2011). Efektivitas dan efisiensi juga perlu diperhatikan agar perusahaan dapat menggunakan dan mengendalikan sumber daya yang dimiliki, baik sumber daya manusia ataupun sumber daya bahan produk. Perusahaan juga perlu memperhatikan faktor manjemennya, karena manajemen yang mengatur keseluruhan kegiatan perusahaan secara efektif dan 
efisien.

Konveksi Kaos Surabaya merupakan konveksi yang menyediakan jasa pembuatan kaos custom yang beralamat di Jalan Ngagel Wasana III 47 Baratajaya, Kecamatan Gubeng, Surabaya, Jawa Timur. Konveksi ini sudah berdiri sejak 2015 dan memiliki banyak pelanggan di berbagai daerah di Surabaya mulai dari online store sampai offline store.

Konveksi Kaos Surabaya masih belum dapat memaksimalkan strategi dalam kegiatan distribusi dikarenakan keterbatasan unit sarana pendukung seperti kendaraan distibusi serta kurangnya managemen untuk sigap dalam menanganinya, namun apabila ditelusuri dari segi sistem distribusinya, perusahaan ini mampu memaksimalkan laba mereka dari sisi lain,seperti volume penjualan, harga jual, kualitas, dan saluran distribusi. Dan salah satu contoh cara memaksimalkannya adalah dengan metode simulasi.

Konveksi Kaos Surabaya memproduksi produk jadi yaitu baju, maka sebelum dijual atau disalurkan akan diperiksa terlebih dahulu oleh bagian Quality Control (QC) dan selanjutnya akan dibagi menjadi 2 jenis produk, yaitu produk jadi dan produk reject. Setelah lolos dari bagian QC, produk produk tersebut akan dikemas dan dikirim ke masing - masing pelanggan. Produk yang telah sampai ke tangan pelanggan akan di cek kembali untuk mengetahui adanya cacat produk. Apabila terdapat kecacatan maka produk yang cacat tersebut dapat dikembalikan (retur).

Karena tidak memiliki cara perhitungan khusus maka banyak kendala yang terjadi pada Konveksi Kaos Surabaya, seperti tidak adanya kontrol untuk mengatasi kegagalan produksi, target pasar kadang terpenuhi dan kadang juga tidak, tidak adanya sistem evaluasi kinerja karyawan atau evaluasi perangkat untuk produksi baju. Sehingga produksi yang dilakukan Konveksi Kaos Surabaya kurang optimal.

Cara mengatasi hal - hal tersebut. Konveksi Kaos Surabaya harus memperbaiki sistem yang mengontrol bagian produksi untuk diperhatikan lebih serius. Hal tersebut yang bisa memicu pihak manajemen Konveksi Kaos Surabaya mengembangkan model simulasi, dan jumlah permintaan yang berfluktuasi atau permintaan yang naik turun.

\section{TINJAUAN PUSTAKA}

\section{Penelitian Terdahulu}

Dalam penelitian dari (Kusumawati, 2011) yang isinya bertujuan untuk menghitung tingkat keuntungan dari distribusi sarung ke daerah pelanggan.

Dalam penelitian lainnya dari (Laksmayana \& Suryani, 2013). Penelitian ini bertujuan untuk mengetahui skenario terbaik untuk memperluas saluran distribusi.

\section{Anylogic}

AnyLogic adalah perangkat lunak yang menyediakan antarmuka grafis yang membantu proses memodelkan lingkungan yang kompleks, seperti manufaktur dan rantai pasok, perawatan kesehatan, pertambangan, atau lalu lintas jalan, sistem pertahanan dan masih banyak lagi (Anylogic, 2019).

\section{Pemodelan dan Simulasi}

Simulasi adalah program komputer yang mempunyai fungsi menirukan perilaku tertentu dalam suatu sistem yang nyata. Tujuannya untuk pelatihan, studi perilaku sistem, dan permainan (Rahardi, 2015).

Proyek simulasi bisa di katakan berhasil membutuhakan kombinasi metode kualitatif dan kuantitatif keterampilan, dukungan kuat dari berbagai bidang organisasi, dan seprangkat alat dan teknik yang dapat meningkatkan efektivitas dan inovasi (Kadir, 2019).

Pemodelan dan simulasi merupakan salah satu alat yang sering digunakan oleh manajemen untuk mempelajari atau menganalisis perilaku dari suatu sistem atau proses

\section{Distribusi}

Distribusi merupakan salah satu kegiatan pemasaran yang bertujuan menyalurkan dan mengirimkan barang dan jasa dari produsen kepada konsumen(Dimiyati, 2018). 
Dalam pengertian lain distribusi diartikan sebagai pemindahan barang dan jasa dari satu sumber kepada konsumen sampai ke tingkat akhir dengan tepat waktu(Assauri, 2004)

Dengan demikian distribusi merupakan salah satu kegiatan pemasaran yang mempunyai tujuan menyalurkan, mengirimkan dan memindahkan barang atau jasa dari satu sumber produsen kepada konsumen sampai ke tingkat akhir dengan tepat waktu(Kurniawaty, 2018).

\section{METODE PENELITIAN}

Metode yang digunakan ialah kualitatif dengan tujuan agar fokus penelitian sesuai dengan fakta di lapangan(Latif, 2018), sedangakan teknik pengumpulan data yang digunakan untuk penelitian ini :

\section{Wawancara}

Tahap wawancara dilakukan dengan salah satu pegawai yang bekerja di Konveksi Kaos Surabaya untuk mengajukan pertanyaan terkait penelitian(Harrell, C. \& R.O. Bowden, 2003).

2. Studi Pustaka topik yang sesuai dengan penelitian sebagai acuan dan bahan penelitian(Siregar, 2018).

Pemodelan dan Simulasi yang digunakan dalam penelitian ini menggunakan aplikasi Anylogic dengan beberapa tahap(Mahpudin, 2018), yaitu :

A. Penentuan Tempat Distribusi.

Membuat database untuk tempat distribusi yang akan digunakan untuk pengiriman.

B. Alur Proses Distribusi

Penggambaran model alur dari proses distribusi yang akan dilaksanakan menggunakan anylogic.

C. Simulasi 3D

Proses simulasi 3D menggunakan anylogic.

\section{Hasil dan Pembahasan}

Dari hasil wawancara diperoleh data lokasi distribusi yang ditunjukan pada tabel 1 berikut :
TABEL 1

LOKASI DISTRIBUSI

\begin{tabular}{|c|l|}
\hline No & \multicolumn{1}{c|}{ Lokasi } \\
\hline 1 & $\begin{array}{l}\text { Gubeng, Surabaya, Jawa Timur, } \\
\text { Indonesia }\end{array}$ \\
\hline 2 & $\begin{array}{l}\text { Wonokromo, Surabaya, Jawa Timur, } \\
\text { Indonesia }\end{array}$ \\
\hline 3 & $\begin{array}{l}\text { Genteng, Surabaya Jawa Timur, } \\
\text { Indonesia }\end{array}$ \\
\hline 4 & $\begin{array}{l}\text { Manyar Sabrangan, Mulyorejo, } \\
\text { Surabaya, Jawa Timur, Indonesia }\end{array}$ \\
\hline 5 & $\begin{array}{l}\text { Darmo, Wonokromo, Surabaya, Jawa } \\
\text { Timur. Indonesia }\end{array}$ \\
\hline 6 & $\begin{array}{l}\text { Dukuh Pakis, Surabaya, Jawa Timur, } \\
\text { Indonesia }\end{array}$ \\
\hline 7 & $\begin{array}{l}\text { Kertajaya, Gubeng, Surabaya, Jawa } \\
\text { Timur, Indonesia }\end{array}$ \\
\hline
\end{tabular}

Dari tabel 1 disebutkan beberapa lokasi distribusi baju dari konveksi kaos surabaya yang tersebar di berbagai tempat di surabaya.

\section{Alur Proses Distribusi}

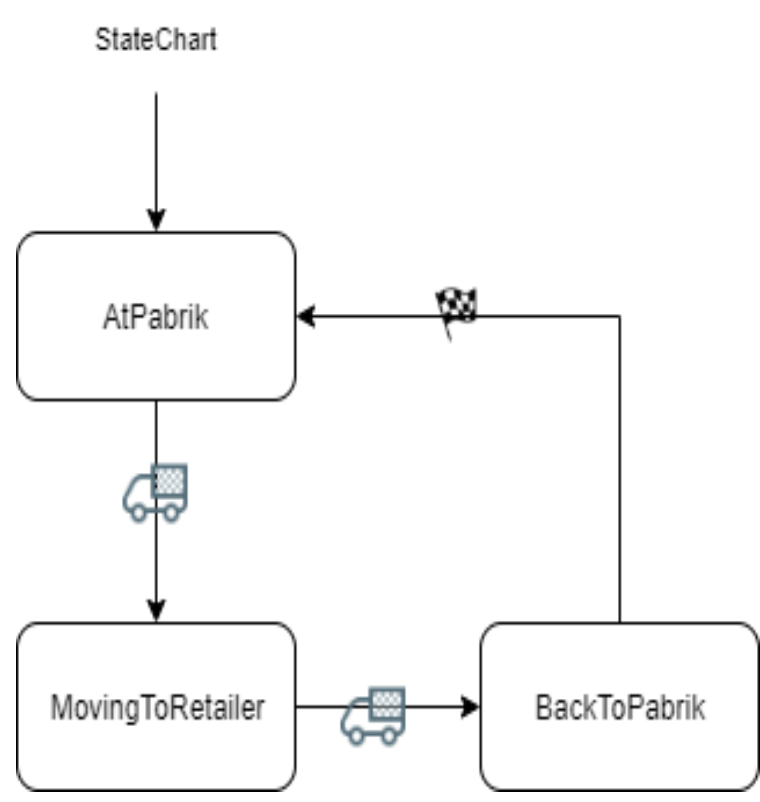

Gambar 1 Alur Proses Distribusi

Gambar 1 menjelaskan alur distribusi yang digunakan oleh konveksi kaos Surabaya yang dimulai dari pabrik langsung ke masing masing retailer, kemudian kembali lagi ke pabrik. 


\section{Simulasi 3D}

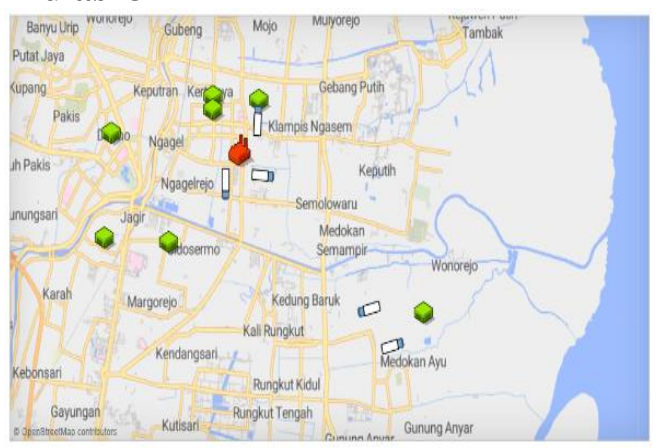

Gambar 2. proses Simulasi 3D

Gambar 2 menjelaskan tempat pabrik dan juga 7 toko retail yang di supply oleh pabrik menggunakan 5 kendaraan, sehingga dinilai kurang efektif dan perlunya diadakan penambahan unit kendaraan disetiap toko retail.seperti dari tabel dibawah:

TABEL 2.

TANGGAL DISTRIBUSI

\begin{tabular}{|c|c|c|c|c|c|c|c|}
\hline \multirow{2}{*}{ truck/gudang } & \multicolumn{7}{|c|}{ tgl sampai gudang tiap bulan } \\
\hline & retal 1 & retail 2 & retail 3 & retail 4 & retail 5 & retail 6 & retail 7 \\
\hline truk1 & 1 & & & & & $1+3$ & \\
\hline truk2 & & 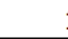 & 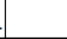 & & & & $1+3$ \\
\hline truk 3 & & & & & & & \\
\hline truk 4 & & & & 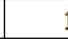 & 1 & & \\
\hline truk 5 & & & & & & 1 & \\
\hline & dikaren & akan a & mbah & vaktu u & ntuk truk & kembali & e pabrik \\
\hline
\end{tabular}

Dari tabel diatas dapat dihitung ketepatan distribusi sebagai berikut:

Ketepatan distibusi

$=\frac{\text { gudang tepat } \text { waktu }}{\text { total gudang }} \times 100 \%$

$=\frac{5}{7} \times 100 \%$

$=71.40 \%$

Total ketepatan waktu distribusi yang dicapai masih $71.4 \%$. Sehingga dibuat penambahan unit sehingga akan menambahkan presentase sesuai dengan tabel dibawah ini:

TABEL 3. SIMULASI KETEPATAN DISTRBUSII DISTRIBUSI

\begin{tabular}{|c|c|c|c|c|c|c|c|}
\hline \multirow{2}{*}{ truck/gudang } & \multicolumn{7}{|c|}{ tgl sampai gudang tiap bulan } \\
\hline & retal 1 & retail 2 & retail 3 & retail 4 & retail 5 & retail 6 & retail 7 \\
\hline truk 1 & 1 & & & & & & \\
\hline truk 2 & & & 1 & & & & \\
\hline truk 3 & & & 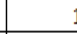 & & & & \\
\hline truk 4 & & & & 1 & 1 & & \\
\hline truk 5 & & & & & 1 & 1 & \\
\hline truk 6 & & & & & & 1 & \\
\hline truk 7 & & & & & & & 1 \\
\hline
\end{tabular}

Dari tabel 3 bisa dibuat:

ketepatan distribusi

$=\frac{\text { gudang tepat waktu }}{\text { total gudang }} \times 100 \%$

$=\frac{7}{7} \times 100 \%$

$=100 \%$

Sehingga total ketepatan waktu distribusi yang dicapai masih $100 \%$ dan ini selisih $28.6 \%$ dari ketepatan waktu distibusi yang diterapkan sekarang..

\section{KESIMPULAN}

Kesimpulan yang didapat dengan menggunakan simulasi distribusi ini diharapkan bisa meningkatkan kualitas dari manajemen konveksi kaos surabaya dalam mengatur naik turunnya permintaan pelanggan, kualitas mutu pelayanan konveksi kaos surabaya meningkat.

Terutama dalam pengiriman oleh pihak distributor. Dengan menambahkan unit sesuai dengan jumlah retail maka ketepatan distribusi bisa mencapai angka maksimal yaitu $100 \%$.

\section{DAFTAR PUSTAKA}

Anylogic. (2019). Introduction to Anylogic Software.

Dimiyati, M. (2018). Laboratorium Simualasi Dan Aplikasi Industri. Retrieved from Academia.edu

Funkfamous, A. (2018). Dasar-Dasar Pemodelan.

Harrell, C., B. K. G., \& R.O. Bowden, J. (2003). Simulation Using Promodel. McGraw-Hill.

Kadir, N. K. (2019). Survey Aplikasi Pemodelan Dan Simulasi Proses Bisnis 
Open Source. Matics, 10(2), 59. https://doi.org/10.18860/mat.v10i2.5164

Kurniawaty, Y. (2018). Simulasi Dan Pemodelan. Retrieved from Academia.Edu

Kusumawati, W. I. (2011).Simulasi Distribusi Produksi Dan Pelayanan Permintaan Sarung Tenun Dengan Monte Carlo.

Laksmayana, N., \& Suryani, E. (2013). Analisis simulasi saluran distribusi busana muslim dengan pemodelan sistem dinamik guna meningkatkan profit (studi kasus: perusahaan habibah busana). 2(1).

Latif, R. (2018). Prinsip-Prinsip Pemodelan Sistem.

Mahpudin, A. (2018). Materi Kuliah Pemodelan Dan Simulasi.

Rahardi, S. S. (2015).Pemodelan Dan Simulasi Distribusi Muatan Pembawa Modelling And Simulation Of Ionic Charge Carrier Distribution In Two Dimensional Anisotropic Fiber Solid. 67-74.

Siregar, H. (2018). Bahasa Simulasi. Retrieved from academia.edu 